\title{
Deficiência em questão: para uma crise da normalidade
}

Joseane de Souza ${ }^{1}$

\section{Sobre a obra}

A obra resenhada trata de posicionamentos pautados em um pressuposto teórico e epistemológico, compartilhada pelos seus autores e organizadores, sobre a deficiência como uma construção cultural, em que historicamente prima por ser conhecida e analisada através de uma perspectiva crítica, revelando ainda formas particulares de opressão de um segmento relevante da sociedade.

\section{A resenha}

O texto que se segue, diz respeito a algumas considerações concernentes à leitura realizada sobre a obra "Deficiência em questão: para uma crise da normalidade". Antes de tecer tais considerações é pertinente, ainda que de forma breve e suscinta, contextualizar o leitor sobre o que se concebe nesse contexto como "deficiência".

$\mathrm{O}$ ativismo político das pessoas com deficiência que vem sendo germinado nos dias atuais, cresceu a partir do surgimento de movimentos sociais alavancado na luta por direitos civis de diferentes ordens, e em vários países ocidentais no final da década 1960 e início dos anos 1970, especialmente no Reino Unido e nos Estados Unidos.

Nesse contexto, a politização das pessoas com deficiências ganhou força ao questionar conceitos considerados puramente biomédicos (medicalização e reabilitação) e que, a partir de então, passa-se a compreender a deficiência como uma questão social.

\footnotetext{
${ }^{1}$ Mestranda em Políticas Sociais pelo Programa de Pós-Graduação em Política Social pela Universidade Federal de Mato Grosso. E-mail: soujosy2@gmail.com
} 
Assim, ao longo das últimas décadas, a politização da deficiência emerge também na academia com os chamados Disability Studies ou Estudos da Deficiência, uma importante corrente teórica/política que discute e pensa a deficiência como uma forma de opressão social. Este pensamento acadêmico/crítico da deficiência vai de encontro à tradicional narrativa hegemônica da modernidade ocidental.

Os estudos nesta área do conhecimento têm avançado significativamente a partir do ativismo dos deficientes, e que no âmbito da academia, estão inseridos nas Ciências Humanas e Sociais. No entanto, no Brasil, esta área de reflexão é praticamente incipiente de produção intelectual, uma vez que existe uma grande carência de pessoas com deficiência no ensino superior, o que se constitui num ambiente propício para a despolitização sobre a questão da deficiência no país. Ainda que haja interesse pelo debate para estas questões, a "deficiência" enquanto eixo central de reflexão permanece ausente em muitos contextos da academia, o que demonstra claramente uma relação de desigualdade que é imposta por ambientes com barreiras socioculturais, psicológicas e físicas que acabam impedindo a participação plena e efetiva dessas pessoas na sociedade.

É dentro desta perspectiva que o livro Deficiência em Questão: para uma crise da normalidade procura dar sua contribuição no sentido de encontrar respostas para algumas questões do campo dos "Estudos da Deficiência". O livro é uma coletânea que resulta da parceria de projetos de pesquisas desenvolvidos no Brasil e no Centro de Estudos Sociais da Universidade de Coimbra em Portugal, instituição esta que tem acolhido e incentivado projetos de estudo alinhados a este pensamento. Essas pesquisas visam articular conhecimento e experiência, que assumam um compromisso político suficiente para denunciar as formas particulares de opressão social, as quais negligenciam as experiências das pessoas com deficiência.

A obra divide-se em nove capítulos sendo que todos eles estão engajados com o pensamento da Disability Studies, tanto no Brasil como em Portugal, apresentando reflexões críticas e emancipatórias do deficiente como ponto de convergência. Cada um desses estudos, dentro de suas especificidades, traz importantes contribuições teóricas e/ou metodológicas para análises críticas que denunciam as questões sociais, culturais e políticas da deficiência.

No primeiro capítulo Bruno Sena Martins reflete sobre as práticas hegemônicas de normalidade e objetificação dos corpos, trazendo-nos importantes teorias e concepções 
do tema, como é o caso de: "técnicas do corpo" (MAUSS), "o habitus e capital simbólico" (BOURDIEU), "símbolo natural" (DOUGLAS) e "o corpo e as relações de poder" (FOUCAUT), tendo nesse último sua principal análise. $\mathrm{O}$ autor afirma que a deficiência não deve estar restrita somente aos saberes da biomedicina, mas que pode ser compreendida como "biopoder", como afirma Foucault, onde o lugar da norma se torna princípio regulador da vida social.

No segundo capítulo da coletânea o texto analisa a questão da emancipação do deficiente, problematizando os Distabily Studies em Portugal (uma vez que a pesquisa foi realizada naquele país), e que metodologicamente oferece olhares para um levantamento bibliográfico sobre a questão. A principal contribuição dos autores está na constatação de que existem poucos estudos acadêmicos sobre a deficiência, necessitando de maior engajamento na compreensão da investigação científica com vistas a um viés ético e político na defesa dos direitos das pessoas com deficiência.

O terceiro capítulo ajuda na compreensão da metodologia da Pesquisa-Ação, pois toda a investigação ocorreu a partir de estudos em grupo, ou seja, os autores retratam a rica experiência deles em realizar uma pesquisa inovadora com um grupo de deficientes visuais e, por isso, o uso da preposição COM para designar a pesquisa. O objetivo de pesquisar COM o outro é diferente de pesquisar sobre o OUTRO.

O quarto capítulo aborda as experiências de uma deficiente visual, que apresenta as dificuldades e os desafios no sentido de se reorientar na mobilidade urbana. As autoras levam em consideração que todos nós interferimos no espaço no momento em que nos deslocarmos, sendo que esta interferência não é somente de ordem geográfica, mas sim práticas de espaço. Para este estudo a relevância está no diálogo com outras áreas, como é o caso da inserção dos estudos da geografia e as teorias de Milton Santos na pesquisa sobre mobilidade humana como prática coletiva e social.

No quinto capítulo são apresentadas as dificuldade e diferenças da deficiência no contexto da escola, que visa debater o sentido da prática de mediação escolar a partir da análise de situações de inclusão vividas no encontro com crianças em situação de inclusão, buscando problematizar a questão do uso do diagnóstico na prática de inclusão escolar. O texto indica os caminhos para lidar com a mediação, o que distancia qualquer perspectiva do ponto de vista da medicalização; a autora sugere noções bastante interessantes para lidar com a direção no ambiente educacional. 
O sexto capítulo dialoga muito com o anterior, pois tem na escola o cenário para a discussão da deficiência. No texto, Luiza Teles Mascarenhas e Marcia Moraes apresentam os desafios da formação de professores na inclusão de alunos com deficiência nas escolas públicas brasileiras. As autoras apontam que, mesmo havendo avanços importantes na legislação brasileira, ainda é preciso combater a desqualificação das diferenças presente ainda na prática de muitos professores. A formação inicial e continuada de professores (formação na perspectiva da racionalidade crítica reflexiva) é fundamental na superação desses paradigmas, assim como é preciso desconstruir a ideia do "mito da competência docente" e a "medicalização da vida escolar".

O sétimo capítulo apresenta a análise de dados como suporte metodológico para pesquisas na área. A proposta das autoras é verificar nos documentos oficiais de domínio público como os boletins de ocorrências usados para analisar a relação existente entre violência contra a mulher e deficiência no estado de Minas Gerais, sendo que a escolha por este estado se deu pelo fato de lá existir uma delegacia especializada no trato a pessoas com deficiência. No entanto, as autoras percebem que ao longo da pesquisa não é possível fazer essa correlação por problemas apresentados nos próprios formulários analisados, uma vez que não existe um campo específico no documento que indique a opção de "pessoa com deficiência" da mulher que sofreu a violência. Constatam ainda, que as políticas públicas voltadas às pessoas com deficiência não trazem a intersecção com as questões de gênero, assim como as políticas públicas voltadas à violência contra a mulher também não fazem intersecção com as pessoas com deficiência. Assim, as autoras apresentam, a partir do conceito de transversalidade, que é importante ocorrer uma aproximação entre direitos humanos, gênero e deficiência.

No oitavo capítulo da coletânea, o autor Fernando Fontes apresenta a violência em Portugal contra o deficiente e os crimes de ódio praticado contra ele. Nesse estudo, Fontes faz um retrato histórico apresentando os principais conceitos de crime de ódio ao longo dos tempos. O autor contextualiza a crise econômica e as políticas de austeridade em Portugal, as quais contribuem para as ondas de ódio contra os grupos minoritários, notadamente contra às pessoas com deficiência. Fontes fez um levantamento do perfil tanto das vítimas como dos agressores, como importante mecanismo de estudo das relações existentes entre os crimes de ódio no grupo de pessoas com deficiência, e ainda 
denuncia os limites das concepções trazidas pelos legisladores quando se trata de crime de ódio contra esses grupos.

No nono e último capítulo da coletânea temos a relevante contribuição de Leonard Davis o qual faz reflexões acerca da arte no contexto da deficiência. Davis apresenta os conceitos de "paradoxo da deficiência e "guetização do visual" já apresentado no título do texto. Pelo paradoxo da deficiência Davis entende o dilema vivido pelo artista deficiente, ou seja, quando sua arte está presente apenas no local ela tem alcance do tema da deficiência, no entanto quando ganha notoriedade daquilo que Davis chama de "universal" o tema deficiência deixa de existir e apaga-se a condição da deficiência do artista e, por consequência, o interesse político e a contribuição que a obra poderia dar dentro da temática.

Os avanços dos estudos desta área, entendem que a deficiência é uma construção social, cultural e política, sobretudo ao enfatizar que não se pode admitir qualquer concepção da deficiência que desconsidere a singularidade da experiência das pessoas com deficiência. Essa coletânea visa desencarcerar a deficiência das intervenções impostas pela área da saúde, a fim de ressignificar novos caminhos que possam modificar as condições estruturais da opressão social sofrida pelos deficientes ao longo da história, sem negar o importante papel que a medicina desenvolve na reabilitação do deficiente.

A inserção da questão da deficiência no espaço acadêmico é fundamental para este processo de mudança. No entanto, ainda que o livro contemple uma discussão acerca da deficiência de maneira significativa do ponto de vista social na academia, há que se pensar que a discussão não deva se limitar a livros e/ou outros gêneros acadêmicos, mas sim trazer o tema a outros espaços de interlocução, como por exemplo, a implantação e implementação de políticas públicas voltadas para pessoas com deficiência.

Nesse sentido, cabe destacar que a implantação das políticas públicas destinadas aos deficientes pouco tem contribuído, uma vez que sua característica principal é pautada pelos princípios que regem a inclusão apenas como um ato de direito, ou seja, a deficiência enquanto ponto central de reflexão permanece invisível pelo Estado, evidenciando assim, o distanciamento entre o que está previsto em lei e o que é praticado pelas ações estatais. Esse distanciamento é percebido nas relações de desigualdade nos espaços físicos e socioculturais, que acabam impedindo a participação plena e efetiva das pessoas com deficiência na sociedade. 


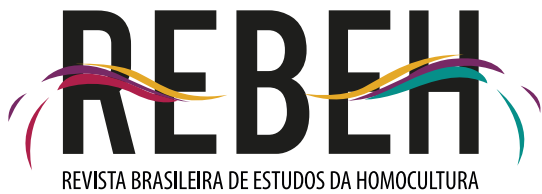

\section{Referências}

MORAES, M. et. al. (Org.). Deficiência em questão: para uma crise da normalidade: 1. Ed. Rio de Janeiro: Nau Editora, 2018.

Recebido em: 24/12/2020

Aceito em: 20/01/2021 